УДК 536.24

\title{
КАК ЭТО БЫЛО... \\ (К 30-ЛЕТИЮ АВАРИИ НА ЧЕРНОБЫЛЬСКОЙ АЭС)
}

Долинский А.А., академик НАН Украины, Басок Б.И., чл-корр. НАН Украины,

Базеев Е.Т., канд. техн. наук

Институт технической теплофизики НАН Украины, ул. Желябова 2а, Киев 03680, Украина

Надано ретроспективний погляд на події, пов'язані 3 аварією на Чорнобильській АЕС. Наведено оцінки та аналіз подій 3 боку громадської і наукової спільноти безпосередньо після катастрофи, а також результати робіт першого етапу (1986-1989 р.р.) 3 ліквідації наслідків аварії, в т. ч. виконаних в ІТТФ АН УРСР. Вказані основні проблеми і наукові роботи, які були актуалізовані аварією на ЧАЕС, направлені на підвищення безпеки атомної енергетики. Підкреслено, що оптимальний вибір енергоресурсів у паливному балансі країни полягає не в протиставленні одних видів енергоресурсів іншим, а в їх розумному, достовірно аргументованому техніко-економічно і екологічно обгрунтованому поєднанні.
Представлен ретроспективный взгляд на события, вызванные аварией на Чернобыльской АЭС. Приведены оценки и анализ событий со стороны гражданской и научной общественности непосредственно после катастрофы, а также результаты работ первого этапа (1986-1989 г.г.) по ликвидации последствий аварии, в т. ч. выполненных в ИТТФ АН УССР. Указаны основные проблемы и научные работы, актуализированные аварией на ЧАЭС, направленные на повышение безопасности атомной энергетики. Подчёркнуто, что оптимальный выбор видов энергоресурсов в топливном балансе страны состоит не в противопоставлении одних видов энергоресурсов другим, а в их разумном, достоверно аргументированном технико-экономически и экологически обоснованном сочетании.
The retrospective view of the events that caused the accident at the Chernobyl nuclear power plant. The estimates and analysis of the events from the civil and scientific societies immediately after the accident, as well as the results of the first stage (1986-1989 years) to liquidation of consequences the accident, including the IET of Ukrainian Academy of Sciences. Named the major problems and scientific works, which were actualized by the Chernobyl accident and directed at improving the safety of nuclear energy. It stressed that the optimal choice of energy in the fuel balance of the country is not in opposition to some other types of energy resources, but their rational, reasoned reliable technoeconomically and environmentally sound combination..

Библ. 15 , табл. 1.

Ключевые слова: авария на ЧАЭС, анализ событий, ликвидация последствий аварии, проблемы атомной энергетики, выбор энергоресурсов.

Уходят в прошлое дни трагических событий, случившихся 30 лет назад на Чернобыльской АЭС (ЧАЭС). Многое в первое время после аварии умалчивалось, некоторые моменты не были оценены в должной степени. Всё, что относилось к технологическим, социальным и политическим аспектам, вызванным аварией, вопросам дальнейшей судьбы атомной энергетики, вызывало бурное обсуждение. Споры выходили за пределы научных дискуссий, велись на митингах, собраниях «зелёных», на страницах массовой печати.

Первым, наиболее крупным собранием специалистов, рассмотревших вопросы энергетического и социально-экономического развития мира после аварии на ЧАЭС, стал XIV конгресс Мировой энергетической конференции (МИРЕК), сос- тоявшийся 17-24 сентября 1989 года в Монреале (Канада). Предметом острых дискуссий стал вопрос о перспективах развития атомной энергетики. Общее мнение участников конгресса свелось к тому, что, несмотря на аварию на ЧАЭС, широкое развитие атомной энергетики в перспективе неизбежно. Но это должно быть связано с созданием реакторов нового поколения, более надёжных и безопасных (реакторов с внутренней безопасностью, обеспечивающей предельно возможный уровень надёжности АЭС). Широкое строительство станций с такими реакторами определялось началом XXI века.

Однако после аварии на ЧАЭС появилось едва ли не главное препятствие на пути развития атомной энергетики - общественное недоверие 
к этой технологии. Развернулись мощные протесты против сооружения новых АЭС и призывы приостановить эксплуатацию уже действующих.

Протесты широкой общественности в Украине вылились в Обращение к XIX Всесоюзной партконференции, подписанное учёными, писателями, работниками Минэнерго УССР, ПЭО Киевэнерго, Южно-Украинской АЭС, НПО “Квант”, Киевского университета им. Т.Г. Шевченко, институтов АН УССР: института геологических наук, математики, геохимии и физики минералов, коллоидной химии и химии воды, физической химии, проблем материаловедения - всего около 4000 тысяч подписей (Літературна Україна, 1988, 23 червня).

Основные аргументы против расширения строительства АЭС в Украине в этом обращении сводились к следующим:

1. Технический брак к выбору площадок и проектирования АЭС. В УССР затруднён выбор площадок по геологическим условиям и ограниченным возможностям водоснабжения. Те площадки, где эксплуатируются и строятся АЭС, выбраны неправильно. Так, сооружение Ровенской АЭС на карстовых землях уже привело к перерасходу на 100 млн. рублей. Строительство Крымской АЭС на тектонических разломах в условиях подъёма грунтовых вод явилось грубой ошибкой. Проект спаренных энергоблоков №3 и №4 на ЧАЭС стал одной из причин гибели людей во время аварии.

2. В Украине ощущается острый дефицит воды. По данным АН УССР, республика по водным ресурсам занимает одно из последних мест в стране. Нецелесообразно подавать воду для охлаждения вводимых энергоблоков на Хмельницкой и Ровенской АЭС из Днестра (240 км.).

3. Игнорирование администрацией АЭС санитарных норм и предписаний органов власти по регулированию и охране воды. На многих АЭС республики происходит сброс перегретой воды и “продувки” прудов-накопителей в реки.

4. Некачественное строительство АЭС. При сооружении станций допускается технический и строительный брак, используются некачественные металл, цемент, и строительные конструкции, что приводит к появлению свищей, трещин и разломов в оборудовании станции.
5. Не решены проблемы захоронения радиоактивных отходов и демонтажа остановленных АЭС.

6. В связи с аварией на ЧАЭС произошло значительное психологическое нарушение в сознании людей, появилось такое социальное явление как радиофобия. Утрачено доверие к атомной энергетике в целом.

7. Слишком высокая реальная стоимость АЭС, которую проектные организации занижают. По данным специалистов, стоимость энергоблоков в США, Японии в 4...5 раз выше, чем у нас.

Эти аргументы против интенсивного наращивания мощности АЭС на территории Украины являлись, по мнению общественности, достаточно весомыми, а из альтернативных развитию атомной энергетики путей наиболее приемлемым следует считать проведение энергосберегающей политики и увеличение мощности тепловой энергетики на органическом топливе с более совершенной очисткой дымовых выбросов и использованием более эффективного оборудования (парогазовые установки).

Авария на ЧАЭС породила огромное количество проблем, затронула многие отрасли экономики и жизнь населения. Для их решения были привлечены многочисленные научные, научнопроектные, промышленные и другие организации и учреждения. Активное участие в работах по ликвидации последствий аварии приняли институты и организации АН УССР, и в том числе, ИТТФ АН УССР. Руководство и координацию работ взял на себя с первых дней аварии директор института чл-кор. АН УССР А.А. Долинский. Ряд работ необходимо было начать практически сразу же после аварии и выполнить в крайне сжатые сроки. Уже 10 мая 1986 года ИТТФ АН УССР приступил к организации проведения работ по теплометрическому анализу - постоянному измерению температуры и теплового потока на развале 4-го блока ЧАЭС. Для диагностики состояния разрушенного блока значительного объёма (105 м3) были применены преобразователи теплового потока и температуры. Определялись аномальные тепловые источники и характер их пространственного распределения, что позволило оперативно оценить места скопления топливосодержащих масс и уточнить количество ядерного 
топлива, оставшегося в объекте. Тем самым специалисты ИТТФ АН УССР внесли существенный вклад в решение проблемы термометрирования разрушенного блока ЧАЭС Детальное описание работ с указанием их исполнителей представлено в $[1,2]$.

Институт продолжал отслеживать состояние разрушенного 4-го энергоблока и в последующие годы. В 1988-89 годах для руководства ЧАЭС актуальным оставался вопрос теплового состояния активной массы разрушенного блока. Институт принял активное участие в работе по расчёту и прогнозированию теплового режима разрушенного реактора в существующем состоянии и для различных вариантов заполнения бетоном пространства под сдвинутой крышкой реактора. По выполнению этой работы представители института д.т.н П.Г.Круковский и к.т.н. Г.В. Коваленко в1989 году выезжали в г. Чернобыль для сдачи работы и обсуждения её результатов на специальном совещании вместе с представителями других научных центров страны, выполнявших также эти работы [2].

Авария затронула и повседневную жизнь людей. Появилась проблема загрязнения радионуклидами продуктов питания, и в частности, питьевого молока. В Министерстве мясомолочной промышленности УССР было принято решение производить питьевое молоко из сухого экологически чистого порошкообразного молока. Институт принял участие в создании мощных технологических линий по растворению сухого молока. Сотрудники института кандидаты технических наук Ю.А. Шурчкова, В.К. Буримский, Б.И. Басок, ст. инж. Л.Д. Королёва, зав.сектором А.И. Васильев во главе с зав. отделом чл-кор. АН УССР А.А Долинским приступили к созданию технологических линий на 3-х молочных завода г.Киева, положив в основу технологию и оборудование, разработанные и изготовленные в ИТТФ АН УССР. Две линии были сданы на заводах №1 и №2 в конце мая и одна линия на заводе №3 в конце июня 1986 года. Выполненная работа помогла обеспечить население г.Киева экологически чистым молоком.

Следствием аварии на ЧАЭС явилась и проблема производства продуктов питания для выведения радионуклидов из организма человека.
К эффективнейшим лечебно-профилактическим препаратам относятся пектиновые вещества. По поручению вице-президента АН УССР академика АН УССР В.П. Кухаря в начале мая 1986 года были начаты работы по использованию такого рода препаратов, и прежде всего, для ликвидаторов аварии. В ИТТФ АН УССР были разработаны технологии получения пектиносодержащих препаратов на основе яблочного порошка. Непосредственными исполнителями работы были: директор института чл-кор. АН УССР А.А Долинский, руководитель отделения института, академик АН УССР О.А.Кремнёв, кандидаты технических наук С.А. Богданов, Р.Ш. Вайнберг, научный сотрудник М.Д. Буцкий, младший научный сотрудник А.В. Лапий. Работы в институте по получению препарата проводились круглосуточно, образцы передавались в Институт микробиологии и вирусологии АН УССР и Институт физической химии АН УССР, а также в Киевский технологический институт пищевой промышленности для выпечки хлеба на основе яблочного порошка, содержащего низкометаксилированный пектин. Хлеб передавался в медицинские учреждения для питания больных - ликвидаторов аварии на ЧАЭС. Динамика выведения радиоизотопов тяжёлых металлов из организма больных определялась в Киевском госуниверситете им. Т.Г. Шевченко и Институте ядерных исследований АН УССР. В специальной справке врачи засвидетельствовали, что потребление полученных сортов хлеба способствовало активизации выведения комплекса радионуклидов на один порядок величин.

Опыт работы на ЧАЭС выявил необходимость использования пектина для оздоровления людей не только в период чрезвычайных ситуаций, но и в повседневной жизни, в частности, сотрудников АЭС, а также тех, кто работает во вредных и тяжёлых условиях других производств. Для этого необходимо было реанимировать промышленное производство пектина в Украине на более высоком, чем в прошлом, научном и технологическом уровнях. В связи с этим, в 19952009 годах в институте под руководством академика НАН Украины А.А. Долинского в отделе тепломассообмена (заведующий отделом к. т. н. Процышин Б.Н.) были проведены новые иссле- 
дования пектинсодержащих веществ, в частности, тыквы с использованием теплофизических, оптических, медикобиологических методов. Результаты исследований позволяют обеспечить в производстве пектина отсутствие твёрдых отходов и вредных газообразных выбросов, экономию энергопотребления, ускорение технологического цикла, выпуск пектиновых веществ с наперёд заданными свойствами, возможность создания новых лекарств, в которых пектин используется как действующее лечебное вещество. Важнейшими народнохозяйственными результатами проведенных работ стало создание инновационных ресурсосберегающих технологий, решение проблем снижения энергозатрат на единицу продукции в производстве пектина и расширение отечественной сырьевой базы для этого производства. Научные и практические результаты работ ИТТФ НАН Украины стали известны за рубежами Украины, вызвав интерес учёных и бизнесменов США, Испании, Индии, России, Беларуси, Аргентины, Японии. Апробация новых технологических решений сотрудниками института была проведена на заводе г. Бар (Винницкая область) и при создании новых производств пектина в Испании и Индии. Были проведены также тестовые технологические работы по запросам фирм США, Аргентины, России. Положительные результаты деятельности Института отражены в отзывах зарубежной прессы и письмах заказчиков. По инициативе банка "Надра" и при поддержке мэра г. Славутич на базе новой отечественной конкурентоспособной на мировом рынке технологии был разработан проект строительства в этом городе производства низкометаксилированного пектина для потребностей работников АЭС Украины. К сожалению, некоторые объективные и субъективные обстоятельства не позволили продолжить эту важную для страны работу. Детальное описание работ, связанных с производством необходимых продуктов питания и лечебно-профилактических препаратов представлено в [1].

Тесное переплетение технологических, нравственных, психологических, социальных и политических вопросов, вызванных аварией на ЧАЭС, работа людей в необычных для большинства условиях повышенной радиационной обстановки, формы опасности, вызывающие у одних пани- ческую настороженность, у других безоглядную беспечность, диктовали необходимость проведения объективной оценки случившегося, отделить домыслы от фактов, поддержать волю людей в борьбе с вышедшей из-под контроля стихией атома. Основная масса людей, привлечённых к ликвидации последствий аварии, и население, жизнь которого затронула авария, не имели представления о принципах действия, технических основах атомных реакторов и возможных следствиях случившегося. А расхожее "взорвался атом" ничего, кроме недоумения и неясного страха, не вызывало.

В этой обстановке обществом “Знание” УССР совместно с АН УССР были организованы выезды специалистов в зону ЧАЭС для выступлений среди ликвидаторов аварии и эвакуированного населения. Наиболее приемлемой формой выступлений была пресс-конференция, проводимая группой из 3-4 различных специалистов. Одна из групп, например, (энергетик, химик-радиолог, медик), в состав которой входил и автор статьи Базеев Е.Т., в своих выступлениях (июнь, сентябрь 1986 года) давала информацию о конструкции и технических характеристиках атомных реакторах РБМК-1000, которыми была оборудована ЧАЭС, характере происшедшей аварии на 4-ом энергоблоке, факторах опасности и основных правилах техники безопасности в период ликвидации аварии на ЧАЭС. Ряд вопросов, просьб и требований ликвидаторов, работающих в зоне ЧАЭС, и населения, проживающего в прилегающих к зоне территориях, передавались по возвращении в г. Киев Правлению общества «Знание» УССР для анализа и решения поднятых проблем [1].

Основные итоги первого этапа ликвидации аварии на ЧАЭС и перспективы научно-исследовательских работ по проблемам, связанным с ликвидацией последствий аварии на ЧАЭС, были рассмотрены на заседании Президиума АН УССР [3]. С докладами выступили чл-кор. АН УССР И.Н. Вишневский (Институт ядерных исследований АН УССР), чл-кор. АН УССР Д.М. Гродзинский (Институт ботаники им.М.Г. Холодного АН УССР), канд. мед. наук В.К. Чумак (Центр экологических проблем ядерной энергетики).

И.Н. Вишневский отметил, что в условиях высоких уровней излучения в первые по- 
слеаварийные дни были проведены измерения, которые показали отсутствие цепной реакции и отсутствие риска проплавления реактора. Создан информационно-диагностический центр “Шатёр", с системой ЭВМ, позволяющей проводить анализ ситуации. Был разработан бытовой радиометр “Припять” для измерения $\beta$ - и $\gamma$-излучения. Использование научно-технических разработок ИЯИ НАН Украины для ликвидации последствий аварии на ЧАЭС более детально представлено в $[1,4])$.

Д.М. Гродзинский считал, что следует придерживаться той точки зрения, что и небольшое повышение радиационного фона может сопровождаться пропорциональным увеличением риска заболевания населения (принцип беспороговости). Работы Института ботаники им.М.Г. Холодного НАН Украины представлены в [1]).

В.К. Чумак подчеркнул актуальность проблемы рационального ведения хозяйства на территориях с повышенным уровнем радиации (необходимо сменить профиль некоторых хозяйств, организовать выпас скота на окультуренных пастбищах).

Острое внимание участников вышеуказанного заседания вызвала "концепция прижизненной дозы 35 бэр”. Что за концепция и откуда она появилась? Речь идёт о разработанной национальной комиссией по радиационной защите (НКРЗ) допустимой “дозы за жизнь” для лиц, оказавшихся на территориях, подвергшихся радиоактивному загрязнению в результате аварии. Это тот предел дозы (35 бэр за жизнь из расчёта 0,5 бэр на человека в год, при средней продолжительности жизни человека 70 лет), на который следует ориентироваться с учётом всех социально-экономических условий, складывающихся в каждом конкретном населённом пункте, районе, области для принятия решений об отселении или возможности дальнейшего проживания на рассматриваемых территориях.

Основными оппонентами по выдвинутым НКРЗ положениям и по утверждённому на их основе Минздравом СССР нормативу выступили учёные Академий наук Белоруссии и Украины. Их возражения в свою очередь явились одной из причин подготовки и подачи в 1989 году в адрес М.С. Горбачёва (тогда Председателя Верховного
Совета СССР) заявления группы учёных, работающих в области радиационной безопасности и радиационной медицины, в связи с ситуацией, обусловленной аварией на ЧАЭС. Заявление подписали 92 учёных (32 из Москвы, 4 - Обнинска, 6 - Минска, Гомеля, 8 - Ленинграда, 29 - Челябинска, 13 - Киева). Полный его текст был издан в качестве экспресс-информации тиражом всего 250 экземпляров и до специалистов и населения он, естественно, не дошёл. Впервые заявление полностью было опубликовано в [5]. В нём приведены аргументы сторонников концепции "35 бэр за жизнь" и рассмотрены альтернативные возражения к установлению такой дозы за жизнь при использовании его в качестве критерия для отселения жителей из зоны ЧАЭС [6]. Отношение к позиции учёных, подписавших заявление, среди специалистов было неоднозначным: преобладали крайние и противоречивые оценки, т. к. "35-берная концепция" затрагивала интересы миллионов людей и здесь было не обойтись без научных дискуссий и общественного обсуждения.

Итоги дискуссии по медико-биологическим вопросам подвёл академик АН Украины В.И. Скок. По его мнению, долгосрочное влияние малых доз облучения от радионуклидов, поступающих в организм человека с продуктами питания, ещё не изучено. Доза в 35 бэр, которую могут получить люди (допустимая доза), обусловлена не медицинскими, а медико-социальными и экономическими соображениями и учитывает расходы на переселение больших групп населения. Поэтому безусловное принятие концепции допустимой дозы в 35 бэр без ограничений, то есть без дальнейших усилий по снижению дозовой нагрузки, было бы неверным. Такая доза должна рассматриваться только как временная при обязательном снижении её в ближайшие годы. Необходимо обеспечить принцип добровольности при решении вопроса о дальнейшем проживании в зонах с прижизненной зоной облучения (На тот момент международно признанный уровень сос-тавлял 0,1 бэр на человека в год, и, следовательно, при средней продолжительности жизни 70 лет “доза за жизнь” составляла бы 7 бэр).

Выступивший затем президент АН УССР академик Б.Е. Патон отметил эффективность работ по дезактивации сооружений, техники, а также 
химико-технологических методов закрепления пыльных участков местности. Подчеркнул, что нужен новый подход при рассмотрении проблем, вызванных аварией на ЧАЭС. Следует перенести центр тяжести на долгосрочные медико-биологические исследования, ибо речь идёт не о жизни одного или нескольких человек, а о жизни целой украинско-белорусской популяции Полесья. Подход должен быть крайне взвешенным. Одним из важных заданий на ближайшее время должно стать всестороннее научное изучение проблемы целесообразности проживания людей на территориях с повышенными уровнями радиации. Необходимо сконцентрировать усилия на решении таких вопросов, как создание в 30 км зоне ЧАЭС и в зонах “жёсткого" контроля радиационной обстановки заповедников наблюдений за миграцией радионуклидов, усовершенствование форм мониторинга за гидрологией бассейнов Днепра и Десны, поскольку эта зона и примыкающие к ней территории являются по сути уникальным полигоном.

На упомянутом заседании Президиума АН УССР было решено считать, что “концепции прижизненной дозы 35 бэр” не может быть принята безоговорочно, она требует более тщательного научного обоснования и может использоваться только как временная при условиях:

- учёта дозы облучения, полученной за начальный период пребывания на радиоактивно-загрязнённой территории;
- обеспечения желающим возможности отселяться с территории, где прижизненная доза радиации вследствие аварии на ЧАЭС превышает 7 бэр (международная рекомендация для строительства АЭС);

- принятия мер по постоянному максимально возможному снижению дозовых нагрузок, в частности, в сельских районах - путём выпаса скота индивидуального пользования только на чистых пастбищах;

-постоянного контроля состояния здоровья с целью учёта индивидуальных особенностей радиационной чувствительности.

Был утверждён новый состав постоянно действующей комиссии по вопросам, связанным с аварией на ЧАЭС, призванной сосредоточить работу преимущественно на экологических и медико-биологических проблемах (председатель комиссии - вице президент АН УССР академик В.И. Скок).

Что касается масштабов развития атомной энергии на Украине, то, по мнению научной общественности, можно было бы ограничиться мощностью, примерно в 14 млн. кВт (такое решение было принято, в частности, на общем собрании отделения физико-технических проблем энергетики АН Украины 20.03.1989 г.). Планирующие органы настаивали на других вариантах развития атомной энергетики в республике (таблица [7]).

Таблица. Варианты развития атомной энергетики (мощность млн. кВт)

\begin{tabular}{|c|c|c|c|}
\hline \multirow{2}{*}{ АЭС } & \multicolumn{3}{|c|}{ Варианты } \\
\cline { 2 - 4 } & Госплана СССР & Госплана УССР & АН УССР \\
\hline Запорожская & 6 & 6 & 2 \\
\hline Хмельницкая & 6 & 4 & 3 \\
\hline Южно-Украинская & 6 & 4 & 2,8 \\
\hline Ровенская & 4,8 & 2,8 & - \\
\hline Чернобыльская & 3 & 3 & - \\
\hline Крымская & 2 & 2 & - \\
\hline Новая (планировалась) & 4 & - & 13,8 \\
\hline Всего & 31,8 & 19,8 & \\
\hline
\end{tabular}

Данные, приведенные в таблице, были обнародованы на пленуме Украинского респу-

бликанского правления ВНТО энергетиков и электротехников имени академика Г.М. Кржижа- 
новского “Об основах концепции Энергетической программы Украинской ССР на период до 2005 года" (Киев, 14 декабря 1989 года). Как видно, варианты развития атомной энергетики в Украине, предложенные Госпланом УССР и АН УССР, в основном совпадают. Кроме того, АН УССР считала целесообразным полностью вывести из эксплуатации ЧАЭС. Вариант, предложенный Госпланом СССР, вызвал однозначную реакцию у общественности республики: такое наращивание мощности после катастрофы на ЧАЭС считалось завышенным. В конференциях, семинарах по проблемам развития энергетики начали, наряду с энергетиками, принимать активное участие и "посторонние" - специалисты других отраслей науки и техники. Зачастую обсуждение проходило в острых дискуссиях, некоторые выступления были резкими по форме. Это было совершенно новое явление в проведении профессиональных форумов, по сути они начали выполнять роль общественной экспертизы. Появилось противостояние энергетиков и “зелёных". Анализ их взаимоотношений вылился на страницы массовой печати и, в частности, представлен в [8].

Авария на ЧАЭС заставила энергетическую и политическую общественность пристально взглянуть на проблемы технического, экономического и социального характера, связанные с развитием атомно-энергетического комплекса. Надо было принимать меры по решению неотложных задач, вызванных аварией, вырабатывать стратегические направления по развитию атомной энергетики. Не всегда принимаемые решения были аргументировано обоснованными. "Часто политические соображения брали верх над здравым смыслом, экономической целесообразностью и даже над требованиями радиационной безопасности" [4]. Так, например, неоправданно было затянуто (более чем на десятилетие) реализация проекта "Вектор" (утилизация радиоактивных отходов в Чернобыльской зоне), прекращено на десять лет строительства 2-го блока Хмельницкой АЭС и 4-го блока Ровенской АЭС, хотя реакторы были уже готовы на 80\%. Закрытие в 2000 году ЧАЭС породило массу проблем технического, экономического и социального характера [4].

Основные проблемы, стоящие перед атомной энергетикой в мире и в Украине, представлены в
[4,9-13]. По данным МАГАТЭ в 30 странах эксплуатируется 194 АЭС (436 реакторов, мощность 3700049 МВт.), в 14 странах сооружаются 66 новых АЭС. Доля производимой электроэнергии на АЭС в мире составляет 17 \% По трём сценариям, разработанным Мировым энергетическим агентством на период до 2050 года, мощность АЭС сохраняется на современном уровне даже при варианте минимального развития атомной энергетики. Нет никаких оснований отказываться от атомной энергетики и в Украине, необходимо сберечь её доминирующую роль в электропроизводстве в настоящее время и на перспективу. Производство электроэнергии в Украине в последние года было стабильно около 50 \%, а сейчас даже $60 \%$ вследствие дефицита угольного топлива на ТЭС. Однако атомная энергетика безусловно должна быть безопасной. Для этого необходимо решить ряд основных проблем [4,9-13]:

1. Найти решения сложных научно-технических проблем продления ресурса работы действующих атомных реакторов. Через 5-10 лет их проектный ресурс будет исчерпан (реакторы проработали уже около 30 лет). За рубежом термин эксплуатации атомных реакторов прогнозируется до 60 лет. Необходимо также выбрать тип реактора на будущее для замены выбывающих.

2. Решить проблему с отработанным ядерным топливом, в связи с прекращением его вывоза в Россию.

3. Найти и разработать технологии переработки и утилизации радиоактивных отходов.

4. Предложить технологии производства собственного ядерного топлива для реакторов АЭС. В Украине есть основные компоненты для производства топлива (уран, цирконий). В настоящее время 98 \% топлива поставляется из России, лишь $2 \%$ - из транснациональной компании Westinghouse.

5. Найти научно-технические и другие решения, связанные с закрытием ЧАЭС.

Для преодоления барьеров и решения проблем, гарантирующих безопасную эксплуатацию предприятий атомно-промышленного комплекса и его дальнейшее развитие, необходимо обеспечить научно-техническое сопровождение этой отрасли энергетики. При этом в первую очередь 
должны использоваться возможности известных научных учреждений НАН Украины. Ряд уникальных работ в области атомной энергетики и ядерной физики, ведущихся в ИЯИ, Национальном научном центре "Харьковский физикотехнический институт”, Институте прочности им. Г.С. Писаренко, Институте электросварки им.Е.О. Патона и др., детально представлено в [4,9-12]. В Институте экономики и прогнозирования НАН Украины получены результаты исследований взаимосвязей энергетики и экономики с учётом сохранения доминирующей роли атомной энергетики [13].

Проводятся работы, связанные с повышением безопасности атомной энергетики, и в ИТТФ НАН Украины Выполняются фундаментальные исследования гидравлики и теплообмена (научный руководитель работ чл-кор. НАН Украины А.А. Авраменко), направленные на усовершенствование математических моделей и компьютерных программ, используемых для обоснования безопасности АЭС. Наибольший интерес представляет разработка многомерных математических моделей для исследования нестационарных и аварийных процессов в элементах активных зон существующих водо-водяных энергетических реакторах и разрабатываемых ядерных реакторов четвёртого поколения со сверхкритическими параметрами теплоносителя, их верификацию на основе экспериментальных данных, полученных на теплогидравлическом стенде высоких параметров ИТТФ НАН Украины.

Начиная с 2005 года и по настоящее время в Институте проводятся работы (научный руководитель д.т.н П.Г.Круковский) по решению проблем разрушенного блока и сооружаемого Нового Безопасного Конфаймента над Объектом "Укрытие" (существующий саркофаг над разрушенным 4-ым энергоблоком ЧАЭС). Созданы компьютерные модели и выполнен анализ по прогнозированию термогазодинамических процессов в этих сооружениях с целью поддержания заданных параметров и работоспособности инженерных систем и оборудования, обеспечивающих необходимую вентиляцию и предотвращения попадания аэрозоля в окружающую среду в случае его внезапного выброса при демонтаже Объекта "Укрытие". Детально эти работы пред- ставлены в [2].

В настоящее время представлена "Концепция Энергетической стратегии Украины на период до 2035 года" $[14,15]$. В ней названы и концептуальные приоритеты развития атомно-промышленного комплекса. Но концептуальные положения должны быть развёрнуты и детализированы в другом документе государственной важности, а именно: в Государственной целевой экономической программе развития атомно-промышленного комплекса (разработать её предложено в [13]). Органическим разделом должна быть и программа научно-технического сопровождения эксплуатации и развития атомной энергетики.

Препятствует разработке программы развития атомной энергетики и повышенный интерес энергетической (и политической) общественности к использованию в топливном балансе страны возобновляемых источников энергии (ВИЭ). Специалисты атомной энергетики и возобновляемой находят и отбирают аргументы и каждый в поддержку именно “своей” отрасли. Сторонники амбиционных действий по включению в топливный цикл ВИЭ напоминают о трагедии Чернобыля и Фукусимы (Япония, 2011 год) и перечисляют проблемы атомной энергетики. Они же опираются при этом и на идеологию "Парижского соглашения" (принятого в Париже 12 декабря 2015 года во время проведения XXI Конференции Сторон Рамковой конвенции ООН по изменению климата), имплементация положений которого способствует сокращению антропогенных выбросов и содействует низкоуглеродному развитию секторов экономики и составляющих жизнедеятельности человека. Оппоненты же напоминают, что (ВИЭ) - это “рассеянная" энергия и выстраивают ряд барьеров, препятствующих их широкомасштабному использованию: отпускные цены на электроэнергию, получаемую при использовании ВИЭ значительно превышают цену на электроэнергию от АЭС, существуют технические ограничения, связанные с введением мощностей возобновляемой энергетики в Объединённую энергосистему Украины и др.

Оптимальный же выбор видов энергоресурсов в топливном балансе страны состоит не в противопоставлении одних видов энергоресурсов другим, а в их разумном, достоверно аргументи- 
рованном технико-экономически и экологически обоснованном сочетании. Атомная энергетика в ближайшее время сохранит свою доминирующую роль в Объединённой энергосистеме Украины. В свою очередь ВИЭ способны кратно увеличить свою долю прежде всего в энергетическом балансе автономного энергоснабжения (жилищно-коммунальный, бюджетный секторы). При этом современные технологии использования ВИЭ для энергоснабжения позволяют создавать здания с низкой энергетической потребностью (пассивное строительство) или даже зданий со статусом “ноль энергии” [16].

Миновало 30 лет после катастрофы на ЧАЭС. Многое уже сделано в должной степени для усиления безопасности АЭС. Аварии в Чернобыле и в 2011 году в Японии подорвали доверие к атомной энергетике и обострили противостояние между приверженцами и противниками развития атомной энергетики. После аварии в Японии 8 стран (Германия, Италия, Швеция, Япония и др.) заморозили программы ядерной энергетики, но 40 стран (Украина, Россия, Финляндия, Великобритания, Китай, Литва и др.) сооружают или планируют строительство АЭС $[9,10]$.

Несомненно, предприятия ядерно-промышленного комплекса, и в частности АЭС, остаются потенциально особо опасными и являются причиной обеспокоенности общественности и надо быть готовым к кризисной ситуации. Но она может быть управляема, если отношения с общественностью основываются на трёх простых посылках: доверии, предупреждении и организованности.

Научно-теоретические исследования, промышленные разработки, выполненные учреждениями НАН Украины совместно с профильными отраслевыми структурами, закладывают основы новых технологий, призванных гарантировать безопасное обращение с ядерными материалами. Уже есть несомненные успехи и можно надеяться, что научный, научно-технический и производственный кадровый потенциал осознаёт высокую ответственность перед общественностью за всё, что связано с атомной энергетикой.

\section{ЛИТЕРАТУРА}

1. Чернобыль 1986-1987 p.p. Участь установ НАН України у подоланні наслідків катастрофи.-
К.:Академперіодика,2005.-492 с

2. Грищуенко Т.Г., Круковский П.Г., Коваленко Г.В. и дp. Работы института технической теплофизики НАН Украины в решении проблем разрушенного реактора и строящегося Конфайнмента (к тридцатилетию аварии на Чернобыльской АЭС). Промышленная теплотехника. - 2016. T. 38, №2. C.5-18.

3. Для ліквідаціï наслідків Чорнобильської аваріі / Рубрика: «У Президії академії наук Української РСР»// Вісн. АН УСРС, 1989,№ 12 . - С. 11-14

4. Вишневський І.М., Довидовський В.В. Етапи розвитку енергетики після Чернобильскої катастрофи. Вісн. НАНУ, 2016, №4. С. 92-98.

5. Трибуна НТР, 1990. №3-4. - С. 8-9.

6. Там же, 1990. №5-6. - С. 10.

7. Базеев E.T. Атомная энергетика: ответственность перед общественностью, Общество “Знание” Украины. Киев.1991. - 20 с.

8. Базеев Е.T. Энергетики и “зелёные”. К.: Об-во "Знание" УССР, 1989. - 15 с.

9. Воєводин В.M. Актуальні проблеми науково-технічного супроводу безпечного функціонування та розвитку ядерно-енергетичного комплексу України, Вісн. НАНУ, 2014, №8. C. 25-32.

10.Воєводин В.Н. Научное сопровождение ядерной энергетики Украины. Вісн. НАНУ, 2015, №5.- С. 55-58.

11.Шульга М.Ф. Про подовження ресурсу блоків АЕС України Вісн. НАНУ, 2016, №5. C. 29-31.

12.Харченко В.B. Міцність матеріалів та елементів конструкцій задля безпечної експлуатації та подовження ресурсу ядерних реакторів і авіакосмічної техніки. Вісн. НАНУ, 2016, №5.-С. 57-60.

13.Геєиь B.M. Розвиток та взаємодія економічної та енергетичної політики в Україні. Вісн. НАНУ, 2016, №2. С. 46-63.

14.Долінський А.А., Басок Б.І., Базєєв С.T. Стратегія теплозабезпечення населених пунктів України (до обговорення проекту Енергетичної стратегії України на період до 2035 р.) // Вісник 
НАН України. - 2015. №4. - С. 98-105.

15. http://mpe.kmu.gov.ua/minugol/doccatalog/ documen The concept of the Energy Strategy of Ukraine till 2035 (the developer - Ministry of Energy and Coal Industry of Ukraine, 2016). $\mathrm{t}$ ? $\mathrm{id}=245094811$.

\section{HOW IT WAS...}

\section{Dolinsky A.A., Basok B.I., Bazeev E.T.}

Institute of Engineering Thermophysics of the National Academy of Sciences of Ukraine, vul. Zhelyabova, 2a, Kyiv, 03680, Ukraine

The retrospective view of the events that caused the accident at the Chernobyl nuclear power plant. The estimates and analysis of the events from the civil and scientific societies immediately after the accident, as well as the results of the first stage (1986 - 1989 years) to liquidation of consequences the accident, including the IET of Ukrainian Academy of Sciences. Named the major problems and scientific works, which were actualized by the Chernobyl accident and directed at improving the safety of nuclear energy. It stressed that the optimal choice of energy in the fuel balance of the country is not in opposition to some other types of energy resources, but their rational, reasoned reliable techno-economically and
16. Басок Б.И., Божко И.К., Недбайло А.Н., Лысенко О.Н. Поливалентная система теплообеспечения пассивного дома на основе возобновляемых источников энергии // Инженерно-строительный журнал. - 2015. - №6 (58). - С. 32-44. environmentally sound combination.

Key words: Chernobyl accident, event analysis, liquidation of consequences of the accident, nuclear energy issues, the choice of types of energy.

1. Chernobyl in 1986-1987. Participating Institutions NAS of Ukraine in Overcoming Consequences of Accident.-K.: Akademperiodika, 2005. - $492 \mathrm{p}$.

2. Grishchenko T.G., Krukovskiy P.G., Kovalenko G.V. and others. Works of Engineering Thermophysics NASU in Solving the Problems of the Destroyed Reactor and the Construction of Confinement (to the thirtieth anniversary of the Chernobyl accident). Promyshlenaja teplotechnika. 2016. - T. 38, №2. - P. 5-18.

3. Visn. USSR Academy of Sciences, 1989. №12. - P. 11-14.

4. Vishnevsky I.M., Dovydovskyy V.V. Milestones Energy after Chernobyl Accident. Visn. 
National Academy of Sciences, 2016. - №4. - P. 9298.

5. Tribune STR, 1990.- №3-4. - P. 8-9.

6. Ibid, 1990. - №5-6. - P. 10.

7. Bazeev E.T. Nuclear Energy: Public Responsibility. Obshestvo "Znanie" Ukraine. Kiev, 1991. - P. 20.

8. Bazeev E.T. Energy and "Green". K.: Obshestvo "Znanie" Ukraine., 1989. - 15 p.

9. Vojvodin V.M. Actual Problems of Scientific and Technical Support and Safe Operation of Nuclear Power Complex of Ukraine. Visnyk NANU, 2014, №8. - P. 25-32.

10. Vocvodin V.N. Scientific Support of Nuclear Energy in Ukraine. Visnyk NANU, 2015, №5.P. 55-58.

11. Shulga M.F. On the Extension of the Resource Blocks NPP Ukraine. Visnyk NANU, 2016, №5. P. 29-31.

12. Kharchenko V.V. The Strength of Materials and Structural Elements for Safe Operation and Extension of Nuclear Reactors and Aerospace Engineering. Visnyk NANU, 2016, №5.- P. 57-60.

13. Geyets V.M. Development and Economic Cooperation and Energy Policy in Ukraine. Visnyk NANU, 2016, №2. - P. 46-63.

14. Dolinsky A.A., Basok B.I., Bazeev E.T. Heating Strategy for Settlements of Ukraine (to discuss the draft Energy Strategy of Ukraine till 2035) // Bulletin of the National Academy of Sciences of Ukraine. - 2015. №4. - P. 98-105.

15. The concept of the Energy Strategy of Ukraine till 2035 (the developer - Ministry of Energy and Coal Industry of Ukraine, 2016). http://mpe.kmu.gov.ua/minugol/doccatalog/ document?id=245094811.

16. Basok B.I., Bozhko I.K., Nedbaylo A.N., Lysenko O.N. Polyvalent Passive House heating System Based on Renewable Energy Sources // Inzhenerno-stroitelny zhurnal. - 2015. - №6 (58). P. 32-44.

Получено 24.08.2016 Received 24.08.2016 